\title{
Hydroxyapatite crystallinity does not affect the repair of critical size bone defects
}

\author{
Marcio Baltazar CONZ¹, José Mauro GRANJEIRO², Gloria de Almeida SOARES ${ }^{3}$
}

1- DDS, MSc, PhD, Associate Professor of Oral Implantology, Unigranrio University, Duque de Caxias, RJ, Brazil; PhD, Metallurgical and Materials Engineering
Department of the Federal University of Rio de Janeiro, Rio de Janeiro, RJ, Brazil.
2- DDS, MSc, PhD, Associate Professor of the Cell and Molecular Biology Department, Institute of Biology, Fluminense Federal University, Rio de Janeiro,
RJ, Brazil.
3- Eng, MSc, PhD, Associate Professor of the Metallurgical and Materials Engineering Department, Federal University of Rio de Janeiro, Rio de Janeiro, RJ, Brazil.

Corresponding address: José Mauro Granjeiro - Pesquisador Sênior - Diretoria de Programas, Instituto Nacional de Metrologia, Normatização e Qualidade Industrial - Av. Nossa Senhora das Graças, 50 - Prédio 6 - Sala da DIPRO, $1^{\circ}$ Andar - Xerém - Duque de Caxias - Rio de Janeiro - RJ - $25250-020$ - Brasil

- Phone: +55-21-2145-3320 - e-mail: jmgranjeiro@inmetro.gov.br

Received: March 22, 2009 - Modification: November 20, 2009 - Accepted: October 26, 2010

\section{ABSTRACT}

\begin{abstract}
$\mathrm{O}$ bjective: The physicochemical properties of hydroxyapatite (HA) granules were observed to affect the biological behavior of graft materials. The aim of this work was to analyze the tissue response of two HA granules with different crystallinity and $\mathrm{Ca} / \mathrm{P}$ ratio in vivo. Material and Methods: The HA granules were produced in the Biomaterials Laboratory (COPPE/UFRJ). The testing materials were HA granules presenting a $\mathrm{Ca} / \mathrm{P}$ molar ratio of 1.60 and $28 \%$ crystallinity (HA-1), and a Ca/P molar ratio of 1.67 and $70 \%$ crystallinity (HA-2). Both HAs were implanted into a critical-size calvaria rat defects. Results: To note, in the control group, the bone defects were filled with blood clot only. Descriptive and histomorphometric analyses after 1, 3, and 6 months postoperatively showed mild inflammatory infiltrate, mainly comprising macrophage-like and multinucleated giant cells, and an increase in the volume density of the fibrous tissues $(p<0.05)$, which was in contrast to the similar volume density of the newly formed bone and biomaterials in relation to the control group. Conclusion: Thus, we concluded that HA-1 and HA-2 are biocompatible and non-degradable, and that crystallinity does not affect bone repair of critical size defects.
\end{abstract}

Key Words: Hydroxyapatite. Bone grafting. Rats. Histology. Biocompatibility testing.

\section{INTRODUCTION}

In the last decade, great progress was made in the use of grafts in dentistry with the development of the biomaterials that became indispensable for professionals in the areas of bucomaxillofacial surgery, paraendodontic surgery, orthognathic and implants surgery ${ }^{13}$. Bone loss owing to trauma or disease is not only a major socio-economic burden on world healthcare systems, but also results in a reduced quality of life for the patient. Current strategies for repair include bone autograft and allograft, both of which have inherent limitations such as limited supply, increased morbidity, and disease transmission potential ${ }^{18}$.

In this scenario, calcium phosphate (Ca-P) porous ceramics had gained acceptance and these are used in medical-dentistry fields in order to promote bone regeneration, increase, or substitution ${ }^{3}$. Calcium phosphate materials can be found in nature (coralline hydroxyapatite) or can be synthesized by precipitation methods using chemical reagents. Hydroxyapatite (HA), $\mathrm{Ca}_{10}\left(\mathrm{PO}_{4}\right)_{6}(\mathrm{OH})_{2}$, is the well-known and widely studied $\mathrm{Ca}-\mathrm{P}^{12}$. In both medical and dental routine, the term "hydroxyapatite" is sometimes used to describe any Ca-P material. Synthetic Ca-P grafts may be the material of choice, especially when large defects need to be filled. It is generally accepted that these bioceramics are only osteoconductive (have the ability to support tissue growth and bone formation) and non-osteoinductive, i.e., they do not have the ability to form new bones when implanted in non-osseous sites ${ }^{17}$.

Based on their physic-chemical properties, the bone-graft material may be either resorbable or non-resorbable, with respect to the extent of 
dissolution of Ca-P materials. The factors affecting the dissolution properties are similar to those affecting biodegradation or bioresorption ${ }^{5,12,17}$.

Among other physicochemical characteristics, $\mathrm{HA}$ crystallinity and $\mathrm{Ca} / \mathrm{P}$ molar ratio have been reported to affect its solubility ${ }^{1,3,23}$, protein adsorption, and osteoblast attachment ${ }^{28}$, possibly compromising biological responses. However, no in vivo data are available in the literature. In order to achieve this point, the aim of this work is to analyze the tissue response of two HA granules with different physicochemical properties in critical-size calvaria rat defects ${ }^{4}$.

\section{MATERIAL AND METHODS}

\section{Material}

The HA (HA-1 and HA-2) granules (250$1000 \mu \mathrm{m}$ ) were obtained from the HA powder, produced from reactive calcium phosphates at room temperature, in the Biomaterials Laboratory, COPPE, Federal University of Rio de Janeiro (Rio de Janeiro, RJ, Brazil). Previous analysis showed that $\mathrm{HA}-1$ granules presented a $\mathrm{Ca} / \mathrm{P}$ molar ratio of 1.6 and $28 \%$ crystallinity, while the HA-2 granules had a $\mathrm{Ca} / \mathrm{P}$ molar ratio of 1.67 and $70 \%$ crystallinity, as determined by chemical analysis and $\mathrm{x}$-ray diffraction (XRD), respectively (Figure 1). Morphological characterization of the materials was carried out with the help of scanning electron microscopy (Zeiss, model DSM 940A, Oberkochen, Baden-Württemberg, Germany) operating at $20 \mathrm{kV}$ of electron acceleration. To identify the crystalline phases in the biomaterials, an x-ray diffractometer (DRX-Miniflex, Rigaku, Tokyo, Japan) was used, which operated at $30 \mathrm{kV}, 15 \mathrm{~mA}$, and CuKa radiation. The crystallinity of the materials was determined from the DRX patterns according to the methodology proposed by Landi, et al. ${ }^{16}$ (2000).

\section{Surgical procedures}

The ethics committee of Bauru School of Dentistry, University of São Paulo (USP) approved the protocol of the surgical intervention (CEEPA - $\mathrm{N}^{\circ}$ 18/2004). All the procedures were followed under rules of Brazilian College of Animal Experimentation (COBEA).

Forty-five adult Rattus norvegicus (250 g body weight) were submitted to skull surgery under general anesthesia with intramuscular administration of xylazine/ketamine ( $\mathrm{v}: \mathrm{v}$, AgriBrands LtdaTM, Paulinia, SP, Brazil). Briefly, after local trichotomy of the frontoparietal region and vigorous disinfection with iodoform alcohol, the surgical area was isolated and a half moon-shaped incision was made in the lining epithelium of the skull with a \#10 surgical knife. The flap was then raised backwards with a Molt spatula, thus widely exposing the bone surface of the skull. Using a surgical trephine $(8 \mathrm{~mm}$ in diameter), a perforation was made in the parietal bone, under abundant and continuous irrigation with saline solution to avoid any thermal injury, crossing the entire diploe and exposing the dura mater at the bottom of the defect. The defects were filled with blood clot, $\mathrm{HA}-1$, and HA-2 in 15 animals each. Nylon sutures (Ethicon ${ }^{\mathrm{TM}}$, Johnson \& Johnson, São José dos Campos, SP, Brazil) were employed to close the reposed flap of each animal. The animals received water and pelleted food ad libitum.

\section{Histological processing}

The rats were killed by an overdose of the anesthetic agent after 1,3 , and 6 months of surgery. The skullcaps with overlaying skin were collected and fixed in $10 \%$ phosphate buffered formalin for one week, demineralized in Morse solution (50\% formic acid and $20 \%$ sodium citrate, $1: 1$ ) for 40 days, dehydrated in ethanol, cleared with xylene, and embedded in Histosec ${ }^{\mathrm{TM}}$ (Merck, Darmstadt, Germany). Hematoxylin-eosin stained 5- $\mu$ m thick semi-serial section was used for descriptive and histomorphometric analysis.

\section{Descriptive histological analysis}

Using an Axioscop ${ }^{\mathrm{TM}}$ (Carl Zeiss, Darmstadt, Germany), we evaluated the presence of blood clots and inflammatory infiltrates, the intensity of angiogenesis, formation of fibrous tissues, resorption of graft material, reorganization of the periosteum, and bone formation and remodeling.

\section{Histomorphometric and statistical analysis}

We determined the volume density of connective tissue, neoformed bone, and biomaterial on nonsuperposed digital images of the total area of the bone defect obtained using Sony Cyber-Shot (P-83, Tokyo, Japan) digital camera coupled to a microscope (Jenaval-Zeiss, Darmstadt, Germany) under $20 \times$ objective (N.A. 0.55). The digital images $(1280 \times 960$ pixels $)$ segmentation allowed

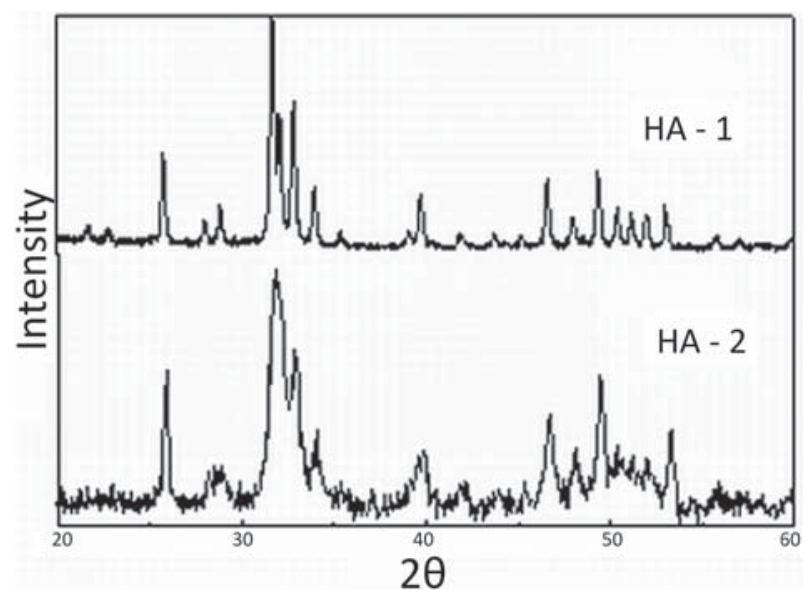

Figure 1- HA-1 and HA-2 x-ray diffraction (XRD) 

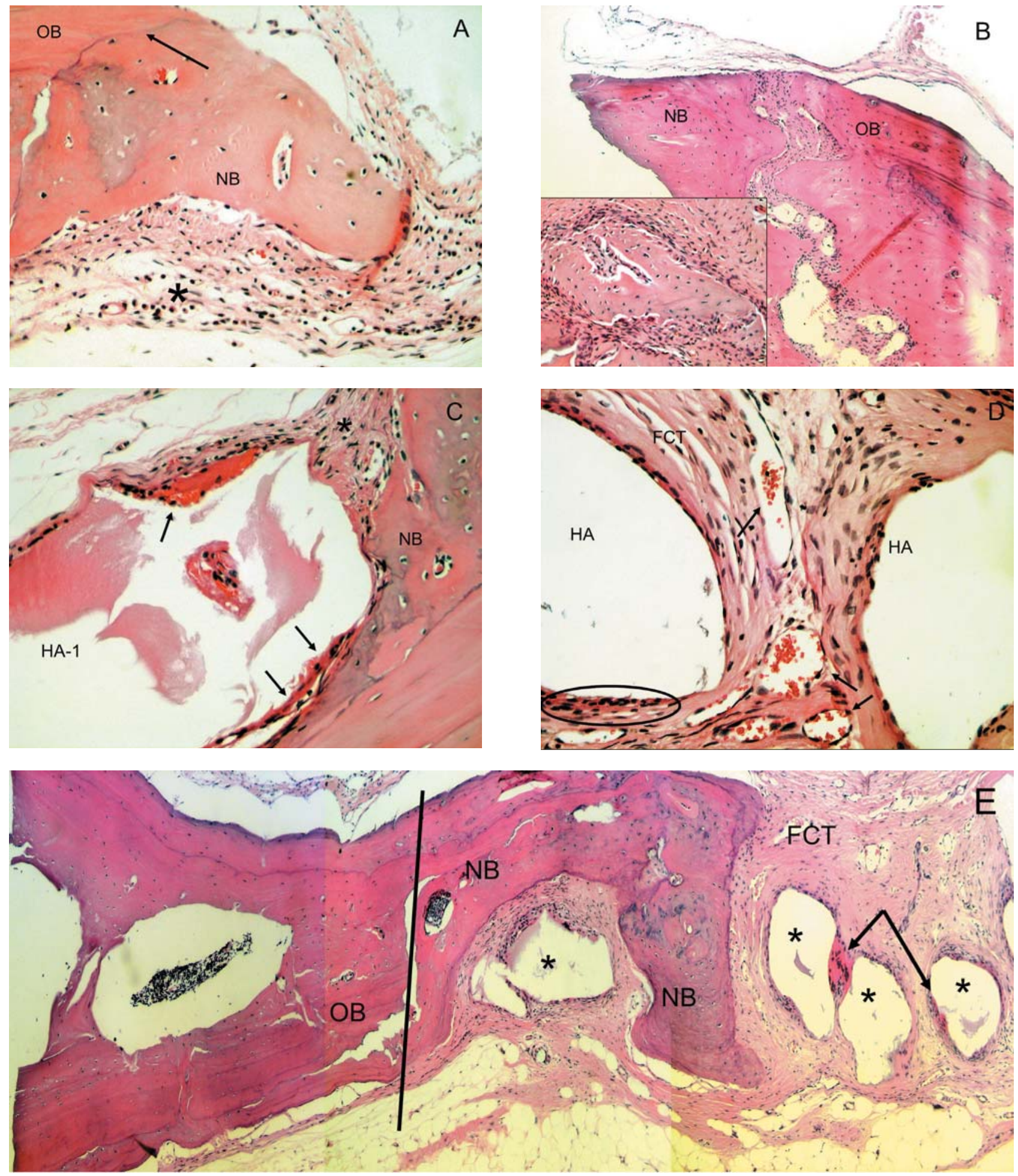

Figure 2- Photomicrography of rat skulls at the periods of 1 and 6 months. A) Control group (blood clot), 1 month; the interface between old bone (OB) and new bone (NB) presents a line (arrow); asterisk $\left({ }^{*}\right)$ shows the connective tissue. B) Control group, 6 months; the old bone (OB) and new bone (NB) separated by connective tissue; interestingly, an animal of five presented endochondral ossification in the center of the bone defect (inner figure). C) HA-1 group, 1 month; presence of new bone (NB) and multinucleated giant cells (arrows) and connective tissue $\left(^{*}\right)$ were observed surrounding HA particles and new bone (NB); D) After 6 months, a fibrous connective tissue (FCT) was enriched by newly-formed blood vessels (arrows) and multinucleated giant cells in contacting HA particles (circle). E) Section showing the border of the bone defect presenting old bone $(\mathrm{OB})$ - new bone $(\mathrm{NB})$ interface (straight line) and HA-2 particles $\left(^{*}\right)$ surrounded by fibrous connective tissue (FCT) close to the border and at the center of critical size defect. Magnifications: 40x (A, C, D, inner figure in B); $12.5 \times(B, E)$ 
determination of the total image area and relative area of the connective tissue, biomaterial, and neoformed bone. Kruskall-Wallis or Mann-Whitney tests determined the existence of significant differences (if $p<0.05$ ) among the volume density of each parameter.

\section{RESULTS}

The procedures were well tolerated by all experimental animals and no complications were observed after surgery.

\section{Descriptive microscopic analysis}

In summary, all groups presented fibrous connective tissues fulfilling the critical-size defect and sparse neoformed bone areas were observed in all the animals, mainly at the edge of defect. No significant difference was noticed between $\mathrm{HA}-1$ and $\mathrm{HA}-2$ and dense connective tissues surrounded the biomaterials granules except for some particles where a directed bone apposition to HA occurred. Tissue response to biomaterials, irrespective of crystallinity and $\mathrm{Ca} / \mathrm{P}$ molar ratio, presented foreign body reaction with multinucleated and macrophagelike cells, occasionally observed in contact with the biomaterials.

Animals from control group, one month after surgery, presented a typical chronic inflammatory infiltrate with a few polymorphonuclear leucocytes close to the blood vessels and mononuclear cells (macrophages-like cells), as showed in the Figure
2A. The presence of polymorphonuclear cells and mast cells was similar in $\mathrm{HA}-1, \mathrm{HA}-2$ and control groups (Figure $2 \mathrm{C}$ ). The macrophages were more abundant surrounding the HA granules, it being multinucleated giant cells (Figure 2C).

The intensity of the inflammatory infiltrate decreased after 3 months of implantation, particularly concerning the presence of macrophages, but with increased incidence of multinucleated foreign body giant cells in both HA-1 and HA-2 groups (not shown). Polymorphonuclear cells were absent in all sections evaluated.

The inflammatory infiltrate disappeared in control group, it being that just an animal (from group of five) showed new bone in the center of the defect after six months (Figure 2B). In both HA-1 and HA-2 groups the microscopic aspects were similar to previous period, presenting mononuclear cells scattered through the dense connective tissue and multinucleated foreign body giant cells around both types of HA particles (Figure 2D and E).

\section{Histomorphometric analysis}

Throughout the experimental periods (Table 1 ), the volume density of connective tissue in the control group was almost twice greater than HA-1 and HA-2 groups $(p=0.012$, Student-NewmanKeuls test). The volume density of bone between tested groups did not change significantly at any experimental period remaining around 30\% after six months. Temporal analysis from one to three months for volume density of connective tissue,

Table 1- Mean percentage ( \pm standard deviation) of the volume density of bone, fibrous connective tissue and residual biomaterial at 1, 3, and 6 months after implantation in critical size bone defect (ANOVA and Tukey test if $p<0.05$ )

\begin{tabular}{|c|c|c|c|c|c|c|c|c|c|}
\hline \multirow{3}{*}{$\begin{array}{l}\text { Analyzed } \\
\text { Structure }\end{array}$} & \multicolumn{9}{|c|}{ Experimental Groups and Periods (months) } \\
\hline & \multicolumn{3}{|c|}{ Control group } & \multicolumn{3}{|c|}{ HA-1 } & \multicolumn{3}{|c|}{ HA-2 } \\
\hline & 1 & 3 & 6 & 1 & 3 & 6 & 1 & 3 & 6 \\
\hline Bone & $22.2 \pm 13.4$ & $21.8 \pm 9.5$ & $32.4 \pm 13.0$ & $15.2 \pm 4.7$ & $25.9 \pm 24.7$ & $27.2 \pm 18.0$ & $21.2 \pm 24.0$ & $21.1 \pm 3.9$ & $32.0 \pm 28.7$ \\
\hline Fibrous tissue & $77.7 \pm 13.4$ & $78.1 \pm 9.5$ & $67.5 \pm 13.0$ & $45.7 \pm 7.2$ & $46.6 \pm 11.2$ & $46.6 \pm 10.5$ & $37.3 \pm 17.5$ & $48.1 \pm 7.6$ & $41.0 \pm 17.0$ \\
\hline Biomaterial & 0 & 0 & 0 & $38.9 \pm 11.8$ & $27.3 \pm 14.14$ & $26.0 \pm 9.1$ & $41.3 \pm 8.0$ & $30.7 \pm 4.2$ & $26.9 \pm 11.8$ \\
\hline
\end{tabular}

Table 2- Percentage of bone, fibrous tissue and biomaterial observed in the present and related studies

\begin{tabular}{lccc}
\hline Author & Bone (\%) & Fibrous tissue (\%) & Biomaterial (\%) \\
\hline Conz, et al. (present work) & 27.2 & 46.6 & 26.0 \\
\hline Conz, et al. (present work) & 32.0 & 41.0 & 26.9 \\
\hline Valentín and Bensur ${ }^{26}(2003)$ & 21.0 & 40.0 & 39.0 \\
Yildirin, et al. ${ }^{29}(2000)$ & 14.7 & 55.6 & 29.7 \\
Norton, et al. ${ }^{22}(2003)$ & 26.9 & 47.5 & 25.6 \\
\hline John and Wenz ${ }^{14}(2004)$ & 29.5 & 55.6 & 14.9 \\
\hline Meijndert, et al. ${ }^{20}(2005)$ & 17.6 & 41.9 & 40.5 \\
\hline
\end{tabular}


bone and HA-1 and HA-2 showed no significant difference (Table 1).

\section{DISCUSSION}

Synthetic and natural Ca-P-based materials may be a suitable alternative to autogenous graft $^{19}$. With various bone grafting options available to the surgeons, one must carefully match the clinical problem with the capabilities of graft material. Sintering process provides strength to a finished material, but when applied to bone, decreases remodeling and resorption capability of the biomaterial ${ }^{11,12}$. Among several factors, chemical composition, particles size, and crystallinity are likely to affect the ceramic solubility, which can be adjusted for the desired purpose ${ }^{7,8}$. Different applications require materials with different resorption rates, which can be regulated by the mixture of several Ca-P phases ${ }^{17}$. Crystallinity is highly dependent on the sintering temperature - the high sintering temperature results in more perfect crystal, and thus, the degradation rate is lesser ${ }^{28}$. On the other hand, more extensive interconnected porosity of materials permits faster bone growth, but it becomes the material weaker; the ideal pore size is considered to be between 150 and 500 microns $^{2,9}$, like those ones naturally designed ${ }^{30}$. Industrially, the degree of microporosity depends on the compaction process of the starting powder and the temperature for producing engineered materials. The presence of pores in the granules increases the surface area in the biomaterials, favoring osteoconduction, and also enabling bone growth in the pores ${ }^{30}$. The HA granules, from both HA-1 and HA-2 groups, presenting different crystallinity (28 and $78 \%$, respectively) and $\mathrm{Ca} / \mathrm{P}$ molar ratio (1.60 and 1.67 , respectively) should present differential biological response. Thus, the positive hypothesis was that less crystalline and calcium-deficient hydroxyapatite (HA-1) presents bigger degradability than others.

Despite many in vivo models available for biocompatibility assay, only critical size defect studies allow the determination of biomaterial efficacy ${ }^{6,25}$. Critical size defect varies in relation to the animal species, localization and animal age; in rat calvaria bone defect of $5 \mathrm{~mm}^{4}$ and $8 \mathrm{~mm}^{10}$ have been widely used. Based on our results, this work supports previous studies that concluded that bone defects of $8 \mathrm{~mm}$ diameter did not allow self regeneration up to six months $s^{5,24}$.

The lack of membrane over the biomaterial for guided bone regeneration (GBR) may explain the high amount of fibrous tissues in the defects ${ }^{10,21}$. As discussed in the current literature, the different densities of fibrous tissues among the experimental groups and control group were related to the HA granules in the defect of the experimental groups 27,31 . GBR has been recognized as a predictable and effective method for enhancing bone healing over a decade, and both animal and human models have illustrated its efficacy ${ }^{15,29}$. It has been shown that the use of absorbable membrane alone was able to fully regenerate a critical size defect ${ }^{25}$.

The experimental groups did not show greater bone formation than the control group, and the results are similar to previous studies in humans ${ }^{14,20,22,26,29}$ (Table 2). It is worthwhile to mention that in the current literature, synthetic and natural hydroxyapatite promoted similar levels of new bone. The residual bone graft biomaterial in the experimental groups increased the mineral content inside the bone defects and did not interfere with the bone formation, acting as an osteoconductor biomaterial. However, the present work is the first evidence comparing in vivo synthetic hydroxyapatites with low (28\%) and high $(70 \%)$ crystallinity and distinct $\mathrm{Ca} / \mathrm{P}$ ratio content, showing that intensity of bone repair was independent of these parameters. An explanation of this statement is that one published recently2; their results revealed key steps of the mechanism for the bioactivity of hydroxyapatite, which are the solubilization of hydroxyapatite and the equilibrium that is formed on the surface. These processes modify the hydroxyapatite surface, whose composition is changed to a new calcium phosphate compound with the chemical formula of $\mathrm{CaHPO}_{4}$. A clear description of the transformations that occur on the surface of hydroxyapatite and of the interplay between these transformations and cell activity are two fundamental aspects of processes in which hydroxyapatite takes part, such as bone substitution, bone remodeling, osteoporosis and caries.

\section{CONCLUSION}

In conclusion, the different characteristics of HA granules did not affect the bone formation in the critical-size defect of rats, despite their biocompatibility. It is known that sintered biomaterials lead to products virtually not absorbable and, thus, developing new strategies to produce absorbable material tend to improve its efficacy. Taken together, these results guide the material engineer for producing biphasic materials containing beta-TCP and non-sintered hydroxyapatite as a potential material to provide bone growth. Another challenge is the production of mechanically stable scaffolds to support the forces applied during surgical procedures. 


\section{ACKNOWLEDGMENT}

We thank CNPq, CAPES, FINEP, MS/DECIT, and FAPERJ for the support of research. We also acknowledge NUCAT/PEQ for the XRD and CETEM/ MCT for facilitating chemical analysis. I also would like to thank Dr. Willian Fernando Zambuzzi for critical review and discussion.

\section{REFERENCES}

1- Accorsi-Mendonça T, Conz MB, Barros TC, Sena LA, Soares GA, Granjeiro JM. Physicochemical characterization of two deproteinized bovine xenografts. Braz Oral Res. 2008;22:5-10. 2- Bertazzo S, Zambuzzi WF, Campos DD, Ogeda TL, Ferreira CV, Bertran CA. Hydroxyapatite surface solubility and effect on cell adhesion. Colloids Surf B Biointerfaces. 2010;78:177-84.

3- Bohner M. Calcium orthophosphates in medicine: from ceramics to calcium phosphate cements. Injury. 2000;31:37-47.

4- Bosch C, Melsen B, Vargervik K. Importance of the critical-size bone defect in testing bone-regenerating materials. J Craniofac Surg. 1998;9:310-6.

5- Carneiro E, Garcia RB, Oliveira RC, Moraes FG, Menezes R, Letra $A$, et al. Microscopic and radiographic analysis of the effect of particle size of demineralized bovine cancellous bone matrix on the repair of bone defects in femurs of rabbits. J Appl Oral Sci. 2005; 13:157-62.

6- Cestari TM, Granjeiro JM, Assis GF, Garlet GP, Taga R. Bone repair and augmentation using block of sintered bovine-derived anorganic bone graft in cranial bone defect model. Clin Oral Implants Res. 2009;20:340-50.

7- Chu TM, Orton DG, Hollister SJ, Feinberg SE, Halloran JW. Mechanical and in vivo performance of hydroxyapatite implants with controlled architectures. Biomaterials. 2002;23:1283-93. 8- Conz MB, Granjeiro JM, Soares GA. Physicochemical characterization of six commercial hydroxyapatites for medicaldental applications as bone graft. J Appl Oral Sci. 2005;13:136-40. 9- Cyster LA, Grant DM, Howdle SM, Rose F, Irvine DJ, Freeman $D$, et al. The influence of dispersant concentration on the pore morphology of hydroxiapatite ceramics for bone tissue engineering. Biomaterials. 2005;26:697-702.

10- Dahlin C, Alberius P, Linde A. Osteopromotion for cranioplasty. An experimental study in rats using a membrane technique. J Neurosurg. 1991;74:487-91

11- Ducheyne PE, Qiu Q. Bioactive ceramics: the effect of surface reactivity on bone formation and bone cell function. Biomaterials. 1999;20:2287-303

12- Fathi MH, Hanifi A, Mortazavi V. Preparation and bioactivity evaluation of bone-like hydroxyapatite nanopowder. J Mat Proc Tech. 2008;202:536-42.

13- Fulmer MT, Ison IC, Hankermayer CR, Constantz BR, Ross J. Measurements of the solubilities and dissolution rates of several hydroxyapatite. Biomaterials. 2002;23:751-5.

14- John HD, Wenz B. Histomorphometric analysis of natural bone mineral for maxillary sinus augmentation. Int J Oral Maxillofac Implants. 2004;19:199-207.
15- Kay SA, Wisner-Lynch L, Marxer M, Lynch SE. Guided bone regeneration: integration of a resorbable membrane and a bone graft material. Pract Periodontics Aesthet Dent. 1997;9:185-94. 16- Landi E, Tampieri A, Celotti G, Sprio S. Densification behavior and mechanisms of synthetic hydroxyapatite. J Eur Ceramic Society. 2000;20:2377-87.

17- LeGeros RZ. Properties of osteoconductive biomaterials: calcium phosphates. Clin Orthop Relat Res. 2002;395:81-98. 18- LeGeros RZ, LeGeros JP, Daculsi G, Kijkowska R. Calcium phosphate biomaterials: preparation, properties and biodegradations. In: Wise DL [editor]. Encyclopedic Handbook of Biomaterials and Bioengeneering. New York: Marcel Dekker; 1995. v. 1, pt. A, p. 1429-63.

19- Marx RE, Garg AK. Bone structure, metabolism, and physiology: its impact on dental implantology. Implant Dent. 1998; 7:267-76.

20- Meijndert L, Raghoebar GM, Schüpbach P, Meijer HJA, Vissink $A$. Bone quality at the implant site after reconstruction of a local defect of the maxillary anterior ridge with chin bone or deproteinised cancellous bovine bone. Int J Oral Maxillofac Surg. 2005;34:877-84.

21- Melcher $\mathrm{AH}$. On the repair potential of periodontal tissues. J Periodontol. 1976;47:256-60.

22- Norton MR, Odell EW, Thompson ID, Cook R. Efficacy of bovine bone mineral for alveolar augmentation: a human histologic study. Clin Oral Implants Res. 2003;14:775-83.

23- Raynaud S, Champion E, Bernache-Assollant D. Calcium phosphate apatites with variable $\mathrm{Ca} / \mathrm{P}$ atomic ratio II. Calcination and sintering. Biomaterials. 2002;23:1073-80.

24- Rose FR, Cyster LA, Grant DM, Scotchford CA, Howdle SM, Shakesheff KM. In vitro assessment of cell penetration into porous hydroxyapatite scaffolds with a central aligned channel. Biomaterials. 2004;25:5507-14.

25- Taga ML, Granjeiro JM, Cestari TM, Taga R. Healing of critical-size cranial defects in guinea pigs using a bovine bonederived resorbable membrane. Int J Oral Maxillofac Implants. 2008;23:427-36.

26- Valentini $P$, Abensur DJ. Maxillary sinus grafting with anorganic bovine bone: a clinical report of long-term results. Int J Oral Maxillofac Implants. 2003;18:556-60.

27- Yamada S, Shima N, Kitamura H, Sugito H. Effect of porous xenographic bone graft with collagen barrier membrane on periodontal regeneration. Int J Periodontics Restorative Dent. 2002;22:389-97.

28- Yang $Y$, Dennison D, Ong JL. Protein adsorption and osteoblast precursor cell attachment to hydroxyapatite of different crystallinities. Int J Oral Maxillofac Implants. 2005;20:187-92. 29- Yildirim M, Spiekermann H, Biesterfeld S, Edelhoff D. Maxillar sinus augmentation using xenogenic bone substitute material Bio-Oss in combination with venous blood. A histologic and histomorphometric study in humans. Clin Oral Implants Res. 2000;11:217-29.

30- Zambuzzi WF, Oliveira RC, Pereira FL, Cestari TM, Taga R, Granjeiro JM. Rat subcutaneous tissue response to macrogranular porous anorganic bovine bone graft. Braz Dent J. 2006;17:274-8. 31- Zitzmann NU, Naef R, Schärer P. Resorbable versus nonresorbable membranes in combination with Bio-Oss for guided bone regeneration. Int J Oral Maxillofac Implants. 1997;12:84452. 